\title{
RISK OF POVERTY AND SOCIAL EXCLUSION IN THE EUROPEAN UNION IN THE CONTEXT OF SUSTAINABLE DEVELOPMENT
}

\begin{abstract}
Sławomir KALINOWSKI, Department of Economics, Poznań Univeristy of Life Sciences, ul. Wojska Polskiego 28, 60-637 Poznań, Poland, kalinowski@up.poznan.pl (corresponding author)

Barbara KIEŁBASA, Faculty of Agriculture and Economics, University of Agriculture in Krakow, Al. Mickiewicza, 31-120 Kraków, Poland, bkielbasa@ar.krakow.pl

This paper addresses the poverty risk issues in the context of sustainable development of rural areas. Empirical materials included in this paper are based on EU-SILC (European Union Statistics on Income and Living Conditions) partial studies, and provide a reference point for comparing the EU income distribution and social integration statistics. Poverty reduction and counteracting social exclusion are among the key Millennium Development Goals. According to studies, one in four inhabitants of EU rural areas is at risk of poverty or social exclusion. While the highest shares of at-risk population are recorded in Bulgaria (54.8\%) and Romania (50.8\%), the levels reported by Poland and Lithuania are also above the EU average (by 4.5 and 9.2 percentage points, respectively). At the other end of the spectrum, the risk rate in the Netherlands and Czech Republic is $12.8 \%$. For the households, income is a factor underpinning their economic safety and, thus, their confidence. The amount of incomes affects the objective poverty levels measured with a parametric method. In the EU, persons earning no more than $60 \%$ of the national median income are assumed to be at risk of poverty. Therefore, the risk of poverty affects nearly every fifth inhabitant of EU rural areas. Poverty and social exclusion are multidimensional aspects which result in unmet needs in multiple areas: healthcare, education, housing, culture and leisure. While triggering some kind of feedback loop, insufficient incomes are both the cause and the effect of deprivation of needs. Also, they provide favorable conditions for an unsustainable development of rural areas.
\end{abstract}

Keywords: at-risk-of poverty rate, rural areas, social exclusion, sustainable development

\section{INTRODUCTION}

In today's world, one of the key challenges is to fight against social exclusion and to support social justice. This is especially true for rural areas which represent a large part of the European Union (ranging from $80 \%$ to $95 \%$ of the land area) and are inhabited by nearly one quarter of the population. Furthermore, almost one third of the population lives in intermediate (urban and rural) areas. The reasons behind fighting the social exclusion in these areas are the increasingly common social inequalities, the material deprivation suffered by a major social group, and the polarization between rural areas and cities. Also, because many problems involved in insufficient incomes and social exclusion are more difficult to diagnose in rural areas, it is hard to address them properly. This includes restricted education opportunities, less labor market opportunities and restricted consumption of goods and services. The level of social inequalities itself is conditioned by the smaller scale of sustainable development. This, in turn, is the consequence of a relationship between the inequalities and the development, and the result of an imbalanced development of four types of capital: social, natural, economic and human capital.

The purpose of this paper is to address the risk of poverty and social exclusion in the context of sustainable development. This paper is supposed to trigger the discussion on how to prevent social inequalities and low standards of living. However, rather than providing ready-made solutions, it only depicts today's situation of rural areas in the EU.

\section{METHODOLOGY}

Empirical materials included in this paper are based on EU-SILC (European Union Statistics on Income and Living Conditions) partial studies, and provide a reference point for comparing the EU income distribution and social integration statistics. EU-SILC has been used since 2003 (initially, in Austria, Belgium, Denmark, Greece, Ireland and Luxemburg; subsequently, from 2004, in all EU countries) to monitor the social policy with the Open Method of Coordination (OMC). These studies are a universal tool focused on incomes, especially including personal income, poverty, social exclusion and standards of living. The population surveyed as a part of EU-SILC is composed of households located in specific 
countries. Surveys are conducted with all household members aged 16 or more. The survey assumes that the employee's income is the total remuneration disbursed in cash or in kind by the employer to the employee in return for work done during a specific period.

\section{RESULTS AND DISCUSSION}

\section{Social inequalities and poverty in the sustainable development concept}

Sustainable development is among the key challenges of today's world (Prus, Mejszelis 2003; Prus, Marszewska, 2009) and among the priorities set by the EU. Although established from 1983 to 1987 by G. Brundtland Commission on Environment and Development (UN G.A., 1987, WCED 1987, 359, Bearth, Beck, Döbel, 2014, 45-46, Borowy, 2013, 199-200), sustainable growth assumptions were adopted for implementation only in June 1992, at the second Earth Summit in Rio de Janeiro (Dernbach, 1998, Dernbach, 2004, 247). During the conference, five documents related to environmental, economic and social matters were enacted, including Agenda 21, Rio Declaration on Environment and Development (which lays down 27 principles and is some kind of a code of human behavior in respect to the natural environment), the Framework Convention on Climate Change, the Convention on Biological Diversity and the Statement of Forest Principles.

An event inherently linked to sustainable development was the adoption of eight Millennium Development Goals at the $2000 \mathrm{UN}$ summit, including the eradication of extreme poverty and hunger; achieving universal primary education; promoting gender equality and empowering women; reducing child mortality; improving maternal health; combating HIV/AIDS, malaria, and other diseases; ensuring environmental sustainability; and developing a global partnership for development (Central Statistical Office, 2011). While all of the above goals are of extreme importance, this paper tackles only the issues of poverty and social exclusion.

Created in 2001, the Sustainable Development Strategy was renewed in June 2006. Its overall aim was to "identify and develop actions to enable the EU to achieve continuous improvement of quality of life both for current and for future generations, through the creation of sustainable communities able to manage and use resources efficiently and to tap the ecological and social innovation potential of the economy, ensuring prosperity, environmental protection and social cohesion" (Central Statistical Office, 2011,7). Cohesion itself may be considered both at an international and interregional level. The latter should involve more than just redressing development imbalances between regions but also evening out differences in incomes and in standards and conditions of living. However, as noted by Churski (2011, 493-512), this may lead to contradictions in the classical approach to regional policy and to rules of regional competition. Therefore, it could be assumed that cohesion itself cannot mean an egalitarian system. Instead, it means attaining a socio-economic level acceptable by the society (cf. Molle, 2015, 241).

Sustainable development is supposed to ensure that the needs of the present generation are met without compromising the ability of future generations to meet their own needs. "It aims at the continuous improvement of the quality of life and well-being on Earth for present and future generations. To that end it promotes a dynamic economy with full employment and a high level of education, health protection, social and territorial cohesion and environmental protection in a peaceful and secure world, respecting cultural diversity" EU SDS 10917/06, p. 2). Sustainable development of rural areas cannot be equated to sustainable agriculture. Instead, it should be seen as the development of the rural community, as emphasized by the importance of various types of knowledge for the development (Zawalińska, 2009, 76). It may be considered under two aspects: not only as actions taken to promote cohesion between the excluded rural groups and the remaining part of the rural society, including the rural population with uncertain incomes, rural freeters and neets, but primarily as actions taken to establish the same development conditions for rural and urban residents and, thus, to enable the rural population to benefit from the positive effects of transformation taking place following the accession to the EU.

It would be difficult to consider a perfect world like More's Utopia where well-being is an inherent part of the society. While social inequalities are common, the governments have the responsibility to establish conditions that address the needs of all citizens. According to the sustainable development concept, economic development cannot be separated from social cohesion, and achieving the right proportion between the economic, human and natural capital should be the key task of all governments. Therefore, the risk (cf. Zielińska-Chmielewska, 2014) of poverty and of failure to meet the needs of the rural population should be looked at as an important factor in this context.

\section{Risk of poverty and social exclusion in rural areas}

Poverty reduction and counteracting social exclusion are among the key Millennium Development Goals. Also, this is a topic of interest to the Common Social Policy for a good reason. One in four inhabitants of EU rural areas is at risk of poverty or social exclusion. This means that one in four inhabitants of rural areas is unable to address his/her needs so as to ensure a healthy and satisfying life. While the highest shares of at-risk population are recorded in Bulgaria (54.8\%) and Romania (50.8\%), the levels reported by Poland and Lithuania are also above the EU average (by 4.5 and 9.2 percentage points, respectively). At the other end of the spectrum, the risk rate in the Netherlands and Czech Republic is $12.8 \%$ (Fig. 1). Also, note the relationship between the total risk in specific countries and the risk of depriving the rural population of their ability to meet their needs. In countries that joined the EU after 2004, these proportions are unfavorable for rural areas (except for Czech Republic), primarily as a consequence of lower levels of agricultural subsidies which continue to be the prevailing income-earning option for the rural population. Other factors that hamper the improvement of the rural population's economic standing are the fragmented agricultural land and the absence of non-agricultural jobs. 
Obviously, insufficient satisfaction of needs is not equivalent to achieving the lower thresholds of biological subsistence and total cultural ignorance. Nevertheless, the social aspect of satisfying the populations' needs is emphasized because the needs are related to aspirations of individuals and to consumption patterns and attitudes transferred both within and between the groups.

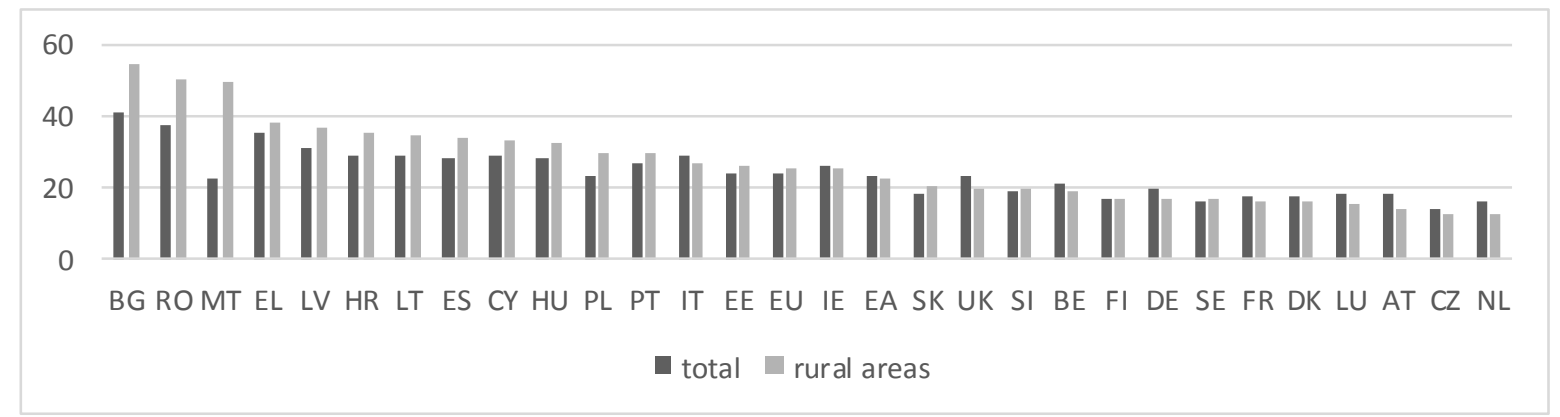

Source: own calculations based on Eurostat.

Figure 1. People at-risk-of-poverty or social exclusion total and on the rural areas

The importance of consumption results from its symbolism. Consumption became an active process whereby the buyer creates its own identity and social status. At the same time, the way the consumption is perceived by one's environment and the way an individual perceives the consumption pattern in his/her environment becomes a factor that defines the satisfaction of needs. This is a bipolar process which both strengthens and weakens the sense of satisfying one's needs. While the market provides the ability to purchase goods and increase the consumption levels, the incomes act as a natural restriction. In economic analyses, incomes are considered to be the main determinant of inequalities whereas qualitative factors are often ignored (Kalinowski, 2015, 179-180). Even though the incomes are only one of the reasons behind social disparity, they are commonly believed to be the key ones (Ortiz, Cummnis, 2011, Milanowic, 2009). But while the incomes significantly affect social cohesion, they cannot be seen as equivalent to the level of cohesion. However, note that the amount of incomes strongly affects the population's purchasing power and the ability to satisfy one's needs. Ultimately, it has an effect on poverty. Insufficient incomes and the absence, uncertainty and irregularity of incomes are an important determinant of the deprivation of needs. Cash held by the population is a key component of material well-being which conditions the proper functioning of households and their sense of economic and social security. As shown by numerous studies, convergence exists between the amount of income and the level of poverty and the inability to fully participate in the society. Therefore, it may be assumed that the relationships between incomes and the degree of deprivation of needs are so considerable that they may be used as a reliable indicator of the conditions of living (cf. 1996, 19). As incomes are an important building block of household security, they affect people's confidence (Kalinowski, 2014, p. 391) which is a major constituent of social cohesion. The amount of incomes affects the objective poverty levels measured with a parametric method. In the EU, persons earning no more than $60 \%$ of the national median income are assumed to be at risk of poverty. Therefore, the risk of poverty affects nearly every fifth inhabitant of EU rural areas. In this case, too, indicators reported by Poland and Lithuania are above the EU average level (Fig. 2).

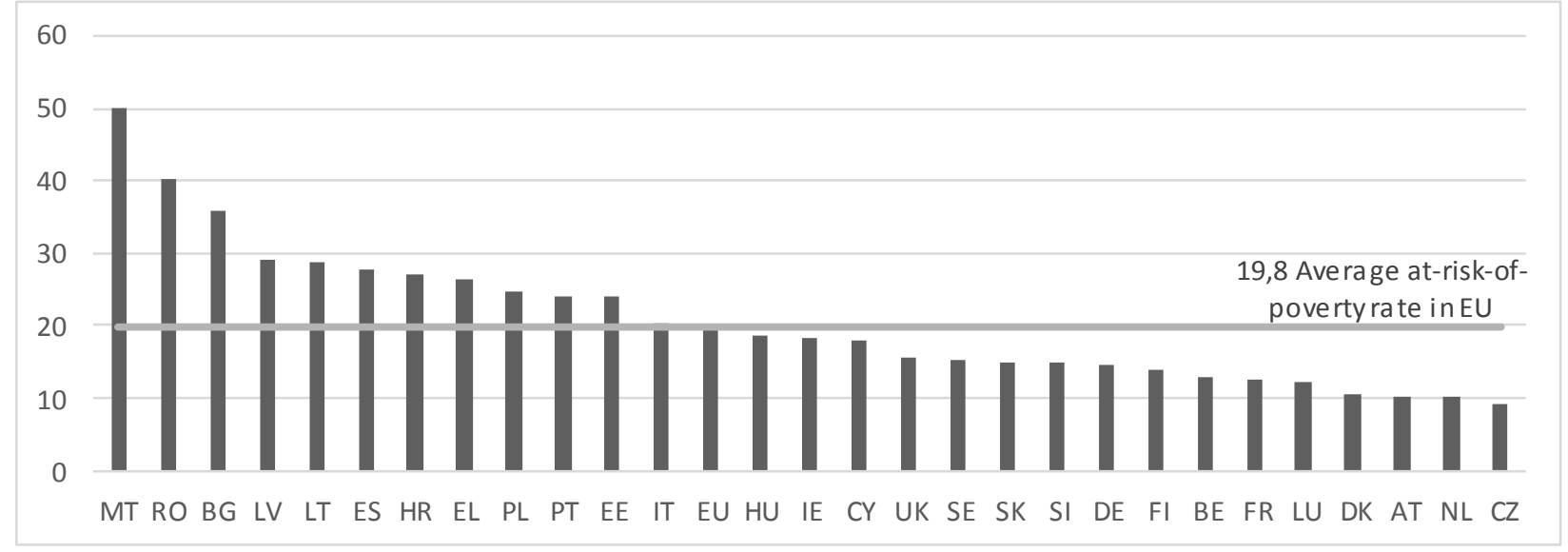

Source: own calculations based on Eurostat.

Figure 2. At-risk-of-poverty rate on the rural areas in 2007-2016

What needs to be looked at is the similarity of specific countries in terms of poverty risk. For that purpose, the Ward's cluster analysis is a useful tool as it allows to group the countries by estimating the distances between clusters based on the variance analysis approach. Five groups of countries were identified with the use of this method. The first one was composed of Belgium, UK, France, Finland, Slovenia, Slovakia and Sweden, with an average at-risk-of-poverty rate of up to $14.3 \%$ (in 2005-2015). The second one included the Czech Republic, Iceland, Denmark, Austria, Luxemburg, 
Norway and the Netherlands. This group demonstrated the lowest at-risk-of-poverty rate (11.2\%) which has continuously decreased over the recent years. The third group comprised Germany, Cyprus, Switzerland, Ireland and Hungary, with a poverty rate close to the EU level (18.2\% on average). The fourth group consisted of Bulgaria, Romania and Malta, reporting the highest rate $(37.2 \%)$ of rural poverty. Members of the fifth group were Estonia, Italy, Poland, Portugal, Greece, Spain, Lithuania, Croatia and Latvia. In these countries, every fourth resident of rural areas was at risk of poverty. Note that in addition to EU countries this analysis also covered three countries from outside the Community which remain closely related to the EU. According to the cluster analysis, the greatest similarity exists between the first and the second group, followed by the similarity between these two groups and the third one. The large distance between the three first groups and the fourth and fifth ones demonstrates the absence of any major similarity between them. What also should be noted is that while rural poverty rates tend to decrease or remain stable in the first three groups, they remain relatively high or grow slightly in the fifth group, and tend to grow consistently in the fourth one (Fig. 3).

Ward's Method

Euclidean distance

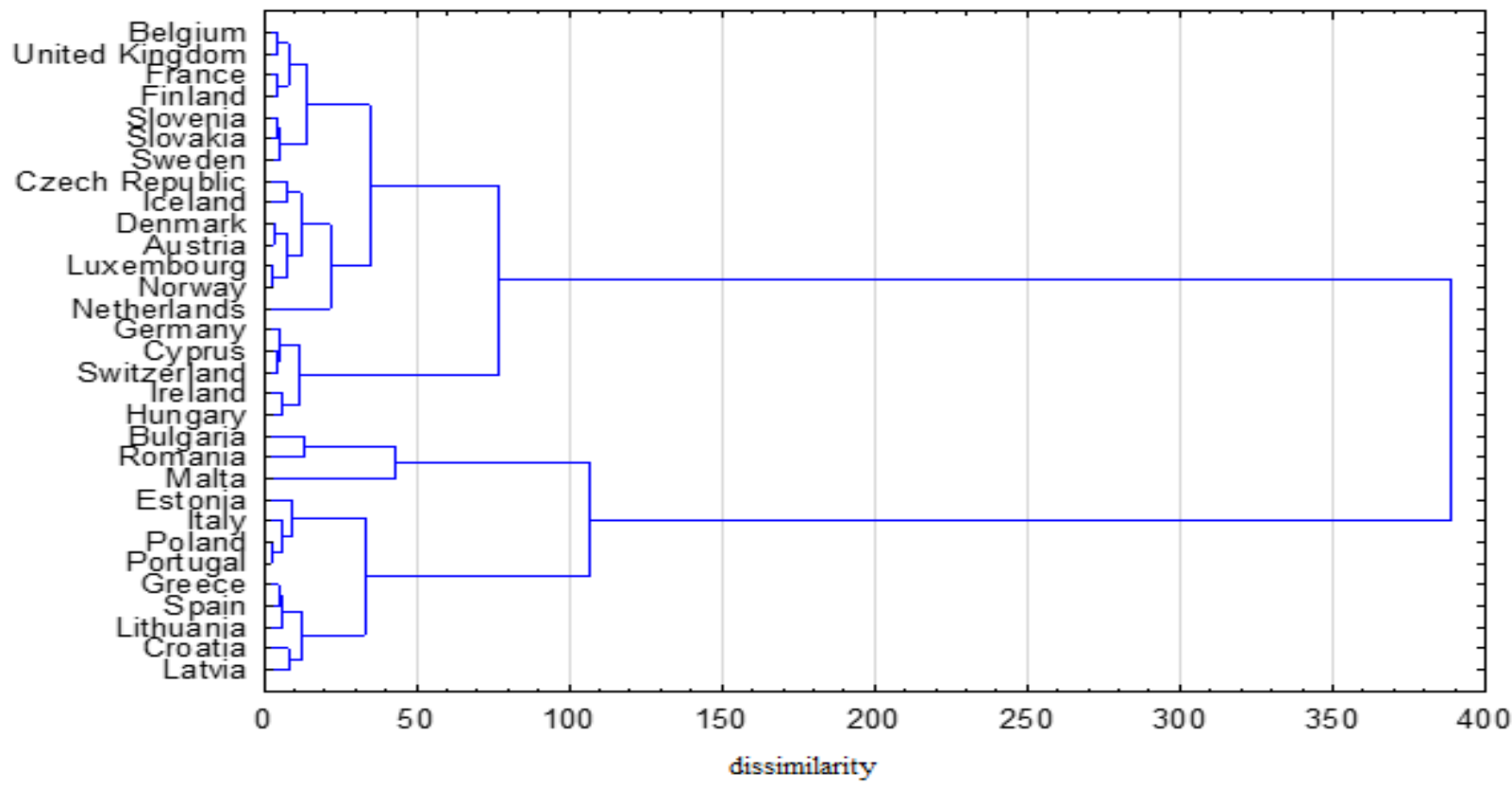

Source: own calculations based on Eurostat.

Figure 3. Cluster analysis - bonds tree diagram Ward method (Euclidean distance)

Note also that poverty and social exclusion are multidimensional aspects which result in unmet needs in multiple areas: healthcare, education, housing, culture and leisure. While triggering some kind of feedback loop, insufficient incomes are both the cause and the effect of deprivation of needs. As a consequence, attitudes are transmitted from one generation to the next, reinforcing the poverty culture (Kabaj, Danceka 2005, p. 132). A disadvantageous income situation undermines social cohesion and makes social participation more difficult. Note also that unmet needs trigger feedback loops, and that cash held by the population determines the scope of real consumption. Therefore, insufficient private demand and holdings (fragmented consumption) usually drives disaffection resulting from an unaccepted standard of living and deprivation of needs (and, as a consequence, from the sense of incoherence). Depriving individuals of the ability to meet their needs loosens social ties, resulting in disintegration. This has a direct effect on the participation in social and public life, manifested by the involvement in NGOs and working for other people as well as by participating in integration activities, including the development of interpersonal skills. Also, this issue affects the way people spend their free time.

\section{FINAL CONSIDERATIONS}

The inability to address one's needs and the resulting sense of exclusion is caused by, and directly related to, the amount of incomes. The sense of incoherence is also the consequence of difficulties faced by individuals who want to achieve expected levels of consumption. The basis for their expectations does not always have to be the maximum satisfaction of needs. Instead, it often is a satisfaction level corresponding to their personal aspirations and situation in previous years. The main cause for the deprivation of needs is the gap between the level of needs met and the consumption aspirations, accompanied by a strong discrepancy between the ability to address one's needs with income from work and the likelihood of addressing those needs through other actions. According to the study:

1. As regards the rural population, the highest rates of poverty or exclusion risks are reported in Bulgaria, Romania, Malta, Greece and Latvia, while the lowest ones are reported in the Netherlands, Czech Republic, Austria and Luxemburg. 
2. If only the incomes are taken into consideration, the highest poverty risk is faced by the population of Malta, Romania, Bulgaria, Latvia and Lithuania, while the lowest one is experienced in the Czech Republic, the Netherlands, Austria and Denmark.

3. The average rate of parametric poverty ( $60 \%$ of median equivalent income) in the EU is $19.8 \%$.

4. EU countries may be classified into 5 groups by the risk of parametric poverty.

\section{REFERENCES:}

1. Bearth, T., Beck, R.M., Döbel, R. 2014. Communicative Sustainability. Negotiating the future from the periphery, Lit Verlag, Berlin.

2. Borowy, I. 2013. The Brundtland Commission: Sustainable development as health issue. Michael, Vol. 10, pp. $198-208$.

3. Churski, P. 2011. Challenges of the cohesion policy vs. the Europe 2020 Strategy, [in:] K. Marciniak, K. Sikora, D. Sokołowski (eds.). Concepts and research problems in geography, Bydgoszcz University of Economy, Bydgoszcz, pp. 493-512.

4. Dernbach, J.C. 1998. Sustainable development as a framework for national governance. Case Western Reserve Law Review, Vol. 49, pp. 1-103.

5. Dernbach, J.C. 2003. Achieving sustainable development: The centrality and multiple facets of integrated decisionmaking. Indiana Journal of Global Legal Studies, Vol. 10, pp. 247-285. https://doi.org/10.2979/gls.2003.10.1.247

6. Golinowska. S. 1997. Research on poverty. Assumptions and method, [in:] Golinowska S. (eds.), Polska bieda II. Kryteria. Ocena. Przeciwdziałanie (Polish poverty II. Assessment. Counteraction.), IPiSS, Warsaw.

7. Kabaj, M., Danecka, M. 2005. Unemployment and social assistance, [in:] Winners and losers of the Polish transformation. Edited by M. Janosz, Oficyna Naukowa, Warsaw, 132.

8. Kalinowski, S. 2014. Pewni niepewności (Certainty of incertitude), [in:] Galor Z., Goryńska-Bittner B., Kalinowski S. (eds.), Życie na skraju - marginesy społeczne wielkiego miasta (Living on the edge: social exclusion in a big city), Societas Pars Mundi, Bielefeld, p. 391.

9. Kalinowski, S. 2015. Poziom życia ludności wiejskiej o niepewnych dochodach (Standards of living of the rural population with uncertain incomes), WN PWN, Warsaw.

10. Milanovic, B. 2009. Global Inequality and the Global Inequality Extraction Ratio: The Story of the Past Two Centuries, Policy Research Working Paper 5044. World Bank, Washington D.C.

11. Molle, W. 2015. Cohesion and growth: is the European Union system fit to face the challenges beyond 2020?, [in:] Facing the challenges in the European Union re-thinking EU education and research for smart and inclusive growth (EuInteg), edited by E. Latoszek et al., PECSA, Warsaw, pp. 239-256.

12. Ortiz, I., Cummnis, M. 2011. Global inequality: beyond the bottom billion. A rapid review of income distribution in 141 countries, UNICEF Policy and Practice, Nowy Jork.

13. Prus, P., Marszewska, A. 2009. Prospects for sustainable development of Bytoń commune in its inhabitants' opinion. Annals of The Polish Association of Agricultural and Agribusiness Economists, Vol. XI, No. 4, pp. 267-271.

14. Prus, P., Mejszelis, M. 2003. Sustainable development of agriculture in the light of the theory of innovations' diffusion and adaptation. Annals of the Polish Association of Agricultural and Agribusiness Economists, Vol. 4, pp. 249-253.

15. Review of the EU Sustainable Development Strategy (EU SDS) — Renewed Strategy. EU Council, 10917/06, Brussels, June 26, 2006.

16. UN General Assembly, Resolution 42/186, Environmental Perspective to the Year 2000 and Beyond, 11 December $1987,2$. Available at http://www.un.org/documents/ga/res/42/a42r186.htm (Accessed on 26/05/2017.).

17. World Commission on Environment and Development (WCED) 1987. Our common future. Oxford, Oxford University Press.

18. Central Statistical Office 2011. Sustainable development indicators for Poland, Katowice.

19. Zawalińska, K. 2009. Instruments and effects of European Union support for regional rural development in Poland, Institute of Rural and Agricultural Development Polish Academy of Sciences, Warsaw.

20. Zielinska-Chmielewska, A. 2014. Risk in business activity and risk management methods in: Nature and conditions of risk, Lodz University of Technology, Łódź, pp. 56-66. 